\title{
Desafio Diagnóstico
}

\section{Dra. Brenda Santamaría ${ }^{1}$ Dra. Ximena Orobio González ${ }^{2}$}
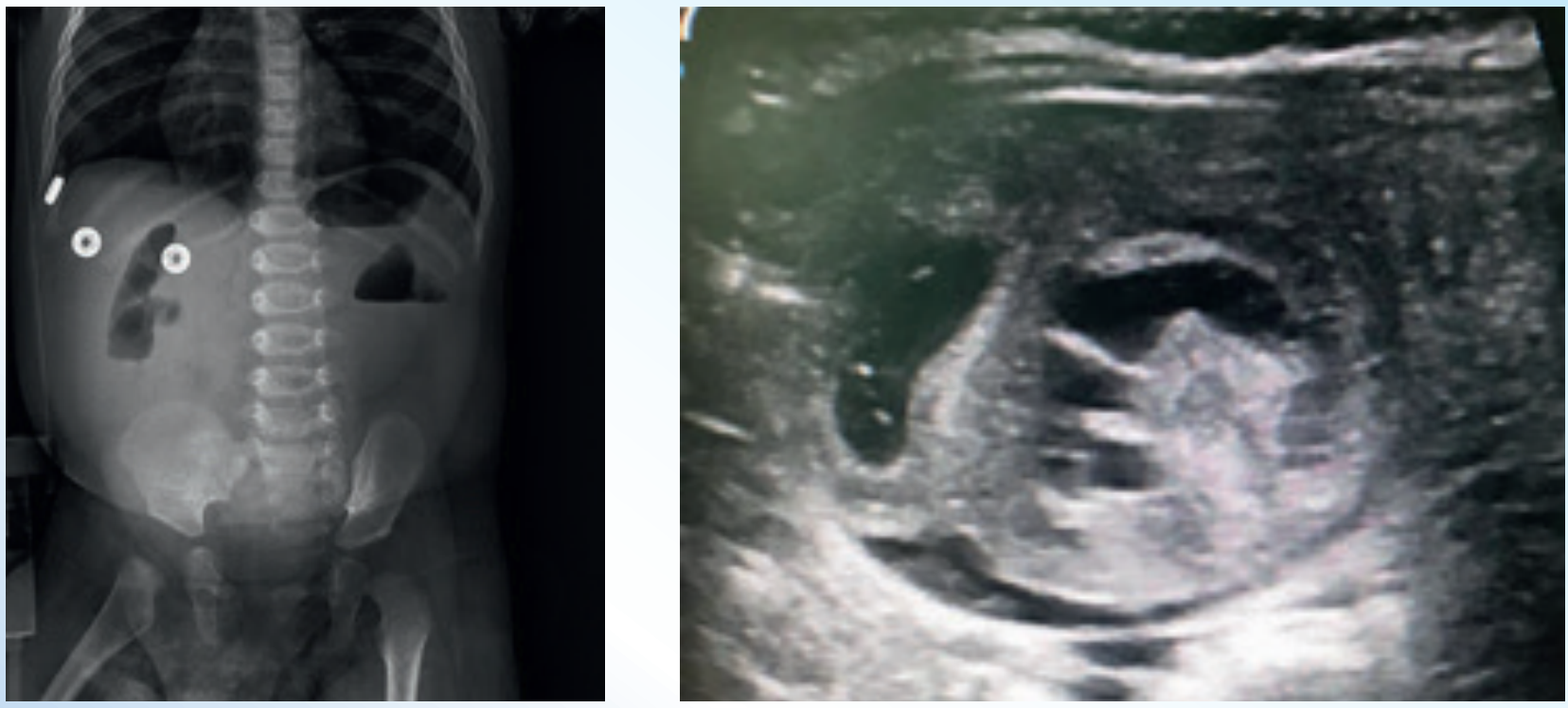

\section{Caso Clínico}

Se trata de lactante masculino de 6 meses de edad, quien consulta por presentar más de 10 vómitos durante la noche, no asociados a diarrea o fiebre. Sin antecedentes patológicos previos conocidos.

Examen físico: con mucosas subhidratadas, resto del examen físico normal.

Exámenes de Laboratorios: Hemograma con leucocitos en 18.400/ $\mathrm{mm}^{3}$ con predominio de neutrófilos. Estudios de gabinete: Rayos $X$ de abdomen y ultrasonido abdominal.

\section{¿Cuál sería su diagnóstico?}

1. Gastroenteritis aguda

2. Hipertrofia pilórica

3. Invaginación intestinal

4. Vólvulos intestinal

' Cirujana Pediatra. Hospital Materno Infantil José Domingo de Obaldía. Chiriquí,

República de Panamá. Correo electrónico: brendayarisa@hotmail.com

${ }^{2}$ Médico Residente Pediatría. Hospital Materno Infantil José Domingo de Obaldía. Chiriquí,

República de Panamá 


\section{Respuesta}

\section{Invaginación intestinal.}

\begin{abstract}
La invaginación intestinal es la urgencia abdominal más frecuente en la infancia y niñez temprana. Es la causa más frecuente de obstrucción intestinal y la segunda de abdomen agudo en la infancia. La incidencia en general es $1-4 \%$, y aproximadamente el $95 \%$ ocurren en los primeros dos años de vida.
\end{abstract}

La intususcepción consiste en que una porción del intestino se introduce dentro de la porción distal adyacente, una vez el intestino permanece introducido, especialmente a través de la válvula ileocecal, su suministro de sangre disminuye cada vez más, hay edema progresivo de la pared del intestino, sangrado de la mucosa, insuficiente suministro de sangre arterial, estasis venosa y finalmente necrosis intestinal.' En la mayoría de los casos la etiología es desconocida, sólo entre 1-11\% están relacionadas con divertículo de Meckel, pólipo y linfoma. ${ }^{2}$

La fisiopatología explica el cuadro clínico típico, donde en la etapa inicial predomina el vómito y el dolor abdominal intermitente, luego este dolor cesa y el niño permanece quieto. Con el incremento de edema en pared del intestino y la disminución del suministro de sangre, pueden presentarse vomito bilioso, distensión abdominal, deshidratación, taquicardia, fiebre y choque. En la etapa final, en el examen rectal pueden verse coágulos mucoides o en jalea de grosellas.

Se pueden realizar varios estudios de imágenes para establecer el diagnóstico: el ultrasonido con doppler color (sensibilidad: 98.5\%, especificidad: 100\%), radiografía de abdomen en dos proyecciones, y el enema diagnóstico.
A nivel mundial, los niños son manejados de manera conservadora, por la alta eficacia de la reducción no quirúrgica. El manejo quirúrgico es importante cuando no se logra una reducción completa, cuando se sospecha una patología adicional o complicaciones como perforación o isquemia intestinal. La recurrencia de aquellos que se reducen con enema es cerca del 9\%, no hay factor predictivo para estimar la recurrencia después de la reducción.

Debido a la baja tasa de recidiva temprana y poco riesgo de complicaciones postdesinvaginación no quirúrgica, se ha propuesto el egreso temprano, luego de vigilancia en cuarto de urgencias por 12 horas en los que se observe si hubo reducción incompleta o recidiva precoz, asegurarse hidratación y tolerancia de la vía oral, de manera tal que se reduzcan los costos hospitalarios y las complicaciones como infecciones nosocomiales al permanecer por mas tiempo hospitalizado. ${ }^{3}$

\section{Referencias}

1. Till H, Sorantin E. Intussusception. 2019. In Puri P, Höllwarth M (eds.), Pediatric Surgery. Springer Surgery Atlas Series, Springer, Berlin, Heidelberg. pp 279 - 285. https://doi.org/ 10.1007/978-3-662-56282-6_32

2. Shojaian R, Majidi S, Hiradfar M, Tajaki H. Retrograde intestinal intussusception due to a recent suture line as the lead point. Journal of Pediatric Surgery Case Reports. 2019; 43 (1): 26-27

3. Dore Reyes M, Triana Junco P, de la Torre C et al. Invaginación intestinal: ¿alta precoz o ingreso por riesgo de recidiva? Cir Pediatr 2016; 29: 110-114. 